\title{
Performance Evaluation of the Metered-Dose Inhaler Technique among Healthcare Providers
}

\author{
Mohammed A. Al Zamil1*, Rabaa Al Momen² \\ ${ }^{1 *}$ Family Medicine Department, Prince Sultan Military Medical City, Riyadh, Saudi Arabia. \\ 2Family \& Community Medicine Department, Faculty of Medicine, King Saud University, Riyadh, Saudi Arabia.
}

\begin{abstract}
Background: Asthma is considered as one of the most common chronic disease worldwide. Literature reveals that the prevalence of asthma in KSA increased significantly from $8 \%$ in 1986 to $23 \%$ in 1995. Pressurized metered dose (pMDI) inhalers are the most cost effective first line of treatment. Formal training and demonstration of the correct use of inhalers have been shown to improve the skills of inhaler use with better outcomes.
\end{abstract}

Objectives: To evaluate the physicians' methods of explaining the MDI techniques to asthmatic patients.

Methods: A total of 165 participants (71 physicians and 94 residency training program members) participated in the study. All the participants were asked to breathe into a placebo MDI device and their techniques were evaluated through a nine step checklist based on the MDI manufacturer's instructions and international guidelines.

Results: No significance difference was found between the performance of male and female participants $(p=0.686)$. Consultants showed a statistically significant difference on performance of steps 1, 4, 7 and 9 when compared to junior, senior residents and registrar $(p=0.027, p=0.006, p=0.030$, $p=0.002$ respectively). For steps $2,3,5,6$ and 8 , no significant

\section{INTRODUCTION}

Asthma is considered as one of the most common chronic disease worldwide. The World health organization (WHO) in 2011, estimated that asthma affects more than 235 million people all over the world. ${ }^{1}$ Moreover, the WHO stated that asthma is the most common chronic disease among children. In the United States, the number of asthmatics has leapt by over $60 \%$ since the early 1980 s and deaths have doubled to 5,000 a year. ${ }^{2}$ The number of disability-adjusted life years lost due to asthma worldwide is approximately 15 million per year. In many western countries, the economic burden of asthmatic patients ranged from $\$ 300$ to $\$ 1,300$ per patient per year. ${ }^{3}$

In the Kingdome of Saudi Arabia (KSA) the prevalence of asthma is not exactly known but studies conducted in the past thirty years reported an overall prevalence ranged of $8 \%$ to $23 \%$ among children. ${ }^{4}$ Comparison of the data of Riyadh versus Hail (an inland desert dry environment) and Jeddah versus Gizan (a coastal humid environment) show that the prevalence of asthma in similar populations increased significantly from $8 \%$ in 1986 to $23 \%$ in difference was found between the groups.

Conclusion: Age and gender has no bearing on the scores but there is a clear trend with the level of professionalism on successful performance of the MDI techniques.

Keyword: Asthma, Pressurized Metered Dose, Pressurized Metered Dose, Physicians.

\section{*Correspondence to:}

Dr. Mohammed A. Al Zamil, ABFM

Senior Registrar,

Family Medicine Department,

Prince Sultan Military Medical City, Riyadh, Saudi Arabia.

\section{Article History:}

Received: 29-10-2016, Revised: 09-11-2016, Accepted: 24-11-2016

\begin{tabular}{|l|c|}
\hline \multicolumn{2}{|c|}{ Access this article online } \\
\hline $\begin{array}{l}\text { Website: } \\
\text { www.ijmrp.com }\end{array}$ & \\
\hline DOI: & \\
10.21276/ijmrp.2016.2.6.041 & \\
\hline
\end{tabular}

$1995 .{ }^{5}$ In KSA, the impact of asthma disease was felt in poor quality of life, loss of work or school days, frequent emergency department visits, hospitalization, and death. ${ }^{4}$

Poor asthma control has been linked to several factors including under diagnosis and inadequate treatment, ${ }^{6}$ poor patient understanding of the disease and its treatment, ${ }^{7}$ non-compliance, ${ }^{8}$ and improper use of inhaler devices. ${ }^{9}$ Inhaled medications are the keystone of asthma treatment. ${ }^{10}$ Poor patient inhaler techniques have been identified as a common and persistent problem by many studies worldwide. ${ }^{11}$

The form of intake is considered the cornerstone of the treatment in asthma. Healthcare professionals use various devices such as spacers, nebulizers, metered dose inhalers, drugs and combinations of these. For years, conventional nebulizers were the only inhalers which were available. The optimum prescribed use of the medication, the technique and the compliance to the medication are important for the control of asthma. The use of inhaled drugs is a basic aspect in the treatment of patients with 
asthma, in acute episodes as well as in maintenance therapy. Inhalation mode of delivering therapy is the main suggested rout as spacers, nebulizers, and metered dose inhalers to achieve a good control of asthma. With the advent of pressurized metereddose inhalers, the delivery of drugs such as bronchodilators and corticosteroids into the respiratory tract was optimized, thereby decreasing the local and the systemic side effects. ${ }^{12}$

A systematic review of clinical effectiveness metered dose inhalers versus other hand held inhaler devices for delivering corticosteroid in asthma concluded that pressurized metered dose (pMDI) inhalers are the most cost effective first line of treatment. ${ }^{13}$ Moreover, another systematic review showed no difference in clinical effectiveness between nebulizers and alternative inhaler devices compared to standard pMDI with or without spacer..$^{14}$

The correct use of inhalers has been shown to be influenced by patients' characteristics, such as their age and their understanding of asthma and its treatment. ${ }^{8}$ Suggesting that, the magnitude of the problem may vary in different populations. Several studies have been conducted among health care providers to evaluate correct MDI technique. Baddar et al., ${ }^{15}$ evaluated the correctness of metered-dose inhaler (MDI) technique in a sample of healthcare providers practicing in Oman. They concluded that the majority of healthcare providers responsible for instructing patients on the correct MDI technique were unable to perform this technique correctly indicating the need for regular formal training programs on inhaler techniques.

Another study was conducted in Iran by Zeraati and Nadi to evaluate the adequacy of metered-dose inhaler (MDI) technique in a sample of physicians and nurses practicing in Hamadan University hospitals. ${ }^{16}$ The majority of healthcare providers responsible for instructing patients on the correct MDI technique were unable to perform this technique correctly. In addition, in India a study was conducted by Dudyala et al., ${ }^{17}$ to evaluate the knowledge regarding the use of pressurized metered-dose inhalers among the professionals. Only $10.9 \%$ of them performed all steps correctly.

Also Stelmach et al., ${ }^{18}$ evaluated residents regarding maintenance treatment of asthma and the technique for using metered dose inhalers. The results demonstrated that, when seeing a typical patient with uncontrolled persistent asthma, most residents were able to correctly identify the drugs indicated for treatment but could not adequately instruct the MDI usage technique.

Formal training and demonstration of the correct use of inhalers have been shown to improve the skills of inhaler use in both patients and healthcare providers. ${ }^{19,20}$ Local baseline information is, therefore, essential for each country to develop its own asthma care services and educational programs targeted at their specific problems and needs. ${ }^{6}$ To the best of our knowledge, no local study had been conducted to address the problem of metereddose inhaler (MDI) technique. Therefore, the objective of this study was to evaluate the physicians' methods of explaining the MDI technique to asthmatic patients.

\section{METHODS}

This cross sectional study was conducted at Prince Sultan military medical city (PSMMC) in Al-wazzarat Health Center, Riyadh, Saudi Arabia. Ethical approval of the department research committee was obtained before conducting the research and informed written consent was taken from each participant. All the family medicine physicians (71), and family medicine residents (94) in the residency training program at Prince Sultan military medical city, PSMMC, in Al-wazzarat Health Center, Riyadh, participated the study.

Data about age, gender, specialty and level of experience (junior, senior, registrar, and consultant) were collected for all the participants.

Each participant was then asked to demonstrate the use of the MDI by taking two puffs from a placebo MDI device. A trained observer, using a checklist of nine steps based on manufacturer's instructions and international clinical guidelines on the MDI technique, ${ }^{21}$ graded the correctness of each participant technique. Steps 1, 4, 5 and 6 were considered essential for proper delivery of the inhaled medications and the remaining steps were classified as recommended for optimal delivery.

Statistical analysis

Data were analyzed using statistical software SPSS (Statistical Package for Social Sciences, IBM, New York) and presented in terms of percentage correct usage of the MDI device. Comparisons were made using a standard chi-squared $\left(X^{2}\right)$ test and $\mathrm{a}<<0.05$ was considered significant.

\section{RESULTS}

A total of 165 (98 male, $59.4 \%, 67$ female $40.6 \%$ ) health care professionals in the Family Medicine Department participated in the study. The mean age of participants was $32.78 \pm 7.3$ years. Majority of them were junior residents $(34.5 \%)$, followed by registrars $(27.9 \%)$ and senior residents $(22.4 \%)$, whereas the consultants were only $15.2 \%$ of the participants (Table 1 ).

Table (2) shows a step-wise evaluation for the major essential steps (1,4,5 and 6).Step 5 showed the highest percentage of correct performance $(92.7 \%)$ followed by $88.5 \%$ for step 6 and $87.9 \%$ for step 1, and the lowest percentage of performance was recorded for step 4 (73.9\%). Regarding other recommended steps, steps 2 and 8 showed the highest percentages of correct performance representing $87.9 \%$ and $68.5 \%$, respectively. Steps 3,7 and 9 showed the lowest percentages of correct performance (28.5\%, 32.7\%, and $23.6 \%$, respectively).

Tables ( $3 \& 4$ ) show the percentage of correct performance in both gender, it was found to be nearly similar in both genders. Comparison of correct performance in relation to gender showed no statistically significant difference in all steps.

Figure 1 shows the distribution of studied physicians in relation to gender and total performance score of meter-dose inhaler technique, the effect of gender on total score performance showed no significant difference of the total score percentage $(p=0.739)$. The high score percentage of $75 \%$ was recorded among $52 \%$ of males and $46.3 \%$ of females. Low score of $<60 \%$ was found to be $17.3 \%$ for males and $17.9 \%$ for females.

Table (5) shows the Comparison of correct performance in relation to professional level, it showed significant differences in steps 1 , 4, 6 and 9. Consultants always had the highest frequency of correct performance of the abovementioned steps. For step one, $77.2 \%$ of junior residents showed correct performance which increased to $89.2 \%$ for senior residents and $93.5 \%$ for registrar while $100 \%$ of consultants correctly performed it $(p=0.012)$. For step four, $63.2 \%$ and $73.0 \%$ of junior and senior residents showed correct performance compared to $73.9 \%$ and $100.0 \%$ among registrar and consultants $(p=0.004)$. The same observation of high 
performance among consultants compared to other groups was observed for steps 6 and 9 where $100.0 \%$ and $52.0 \%$ of consultants performed correctly steps 6 and 9 respectively compared to $78.9 \%$ and $15.8 \%$ among junior and senior residents, respectively ( $p=0.028$ and 0.001 , respectively). For the recommended steps $(2,3,5,6$, and 8$)$ although consultants still showed higher correct performance than other professional levels, the differences were not statistically significant.

Table 1: Demographic data of the studied sample

\begin{tabular}{lccccccccc}
\hline & \multicolumn{4}{c}{ Professional Level } \\
\cline { 2 - 11 } & $\begin{array}{c}\text { Junior } \\
\text { resident }\end{array}$ & $\begin{array}{c}\text { Senior } \\
\text { resident }\end{array}$ & Registrar & Consultant & $\mathbf{2 5 - 3 0}$ & $\mathbf{3 0 - 3 5}$ & $\mathbf{3 5 - 4 0}$ & $\mathbf{4 0 - 4 5}$ & $\mathbf{4 5 - 6 0}$ \\
Males $(\mathbf{n = 9 8})$ & 37 & 23 & 20 & 18 & 37 & 35 & 9 & 8 & 9 \\
Females $(\mathbf{n = 6 2 )}$ & 20 & 19 & 14 & 9 & 36 & 12 & 2 & 5 & 7 \\
Total $(\mathbf{n = 1 6 0 )}$ & 57 & 42 & 37 & 27 & 73 & 47 & 11 & 13 & 16 \\
\hline
\end{tabular}

Table 2: The correct performance in different procedure in all studied subjects.

\begin{tabular}{|c|c|c|c|}
\hline & \multirow[t]{2}{*}{ Procedure } & \multicolumn{2}{|c|}{ Correct Performance } \\
\hline & & No. & $\%$ \\
\hline 1. & Remove cap and shake the inhaler vigorously & 145 & 87.9 \\
\hline 2. & Breath out slowly and completely & 145 & 87.9 \\
\hline 3. & Hold the inhaler in the upright position & 47 & 28.5 \\
\hline 4. & $\begin{array}{l}\text { Insert the mouthpiece into mouth between closed lips or } \\
\text { up to } 4 \text { centimeters in front the open mouth }\end{array}$ & 122 & 73.9 \\
\hline 5. & Depress the canister once & 153 & 92.7 \\
\hline 6. & $\begin{array}{l}\text { At the same time begin slow deep inhalation continue to } \\
\text { total lung capacity (co-ordination) }\end{array}$ & 146 & 88.5 \\
\hline 7. & Remove the inhaler with closed lips & 54 & 32.7 \\
\hline 8. & Hold breaths for $10-15$ seconds. & 113 & 68.5 \\
\hline 9. & Wait for $20-30$ seconds before starting the second puff. & 39 & 23.6 \\
\hline
\end{tabular}

Table 3: Distribution of studied physicians in relation to gender and Correct performance of meter-dose inhaler technique

\begin{tabular}{|c|c|c|c|c|c|c|c|}
\hline \multicolumn{2}{|r|}{ Procedure } & \multicolumn{6}{|c|}{ Correct Performance } \\
\hline & & \multicolumn{2}{|c|}{ Males $(n=98)$} & \multicolumn{2}{|c|}{ Females $(n=67)$} & \multicolumn{2}{|c|}{ Total $(n=165)$} \\
\hline & & No. & $\%$ & No. & $\%$ & No. & $\%$ \\
\hline 1 & Remove cap and shake the inhaler vigorously & 85 & 86.7 & 60 & 89.6 & 145 & 87.9 \\
\hline 2 & Breath out slowly and completely & 88 & 89.9 & 57 & 8.1 & 145 & 87.9 \\
\hline 3 & Hold the inhaler in the upright position & 25 & 25.5 & 22 & 32.8 & 47 & 28.5 \\
\hline 4 & $\begin{array}{l}\text { Insert the mouthpiece into mouth between closed lips or } \\
\text { up to } 4 \text { centimeters in front the open mouth }\end{array}$ & 74 & 75.5 & 48 & 71.6 & 122 & 73.9 \\
\hline 5 & Depress the canister once & 91 & 92.9 & 62 & 92.5 & 153 & 92.7 \\
\hline 6 & $\begin{array}{l}\text { At the same time begin slow deep inhalation continue to } \\
\text { total lung capacity (co-ordination) }\end{array}$ & 89 & 90.8 & 57 & 85.1 & 146 & 88.5 \\
\hline 7 & Remove the inhaler with closed lips & 30 & 30.6 & 24 & 35.8 & 54 & 32.7 \\
\hline 8 & Hold breaths for $10-15$ seconds. & 69 & 70.4 & 44 & 65.7 & 113 & 68.5 \\
\hline 9 & Wait for $20-30$ seconds before starting the second puff. & 25 & 25.5 & 14 & 20.9 & 39 & 23.6 \\
\hline
\end{tabular}

Table 4: Comparison between male and females regarding the correct performance of Meter-dose inhaler technique

\section{Procedure}

Remove cap and shake the inhaler vigorously

Breath out slowly and completely

Hold the inhaler in the upright position

4 Insert the mouthpiece into mouth between closed lips or up to 4 centimeters in front the open mouth

5 Depress the canister once

6 At the same time begin slow deep inhalation continue to total lung capacity (co-ordination)

7 Remove the inhaler with closed lips

8 Hold breaths for $10-15$ seconds.

9 Wait for 20-30 seconds before starting the second puff.

\begin{tabular}{|c|c|c|c|c|c|}
\hline \multicolumn{6}{|c|}{ Correct Performance } \\
\hline \multicolumn{2}{|c|}{$\begin{array}{l}\text { Males } \\
(n=98)\end{array}$} & \multicolumn{2}{|c|}{$\begin{array}{c}\text { Females } \\
(n=67)\end{array}$} & \multirow[t]{2}{*}{$\mathrm{X}^{2}$} & \multirow[t]{2}{*}{$p$} \\
\hline No. & $\%$ & No. & $\%$ & & \\
\hline 85 & 86.7 & 60 & 89.6 & 0.091 & 0.386 \\
\hline 88 & 89.9 & 57 & 8.1 & 0.833 & 0.250 \\
\hline 25 & 25.5 & 22 & 32.8 & 1.04 & 0.198 \\
\hline 74 & 75.5 & 48 & 71.6 & 0.309 & 0.352 \\
\hline 91 & 92.9 & 62 & 92.5 & 0.006 & 0.583 \\
\hline 89 & 90.8 & 57 & 85.1 & 1.28 & 0.187 \\
\hline 30 & 30.6 & 24 & 35.8 & 0.49 & 0.297 \\
\hline 69 & 70.4 & 44 & 65.7 & 0.414 & 0.317 \\
\hline 25 & 25.5 & 14 & 20.9 & 0.469 & 0.311 \\
\hline
\end{tabular}




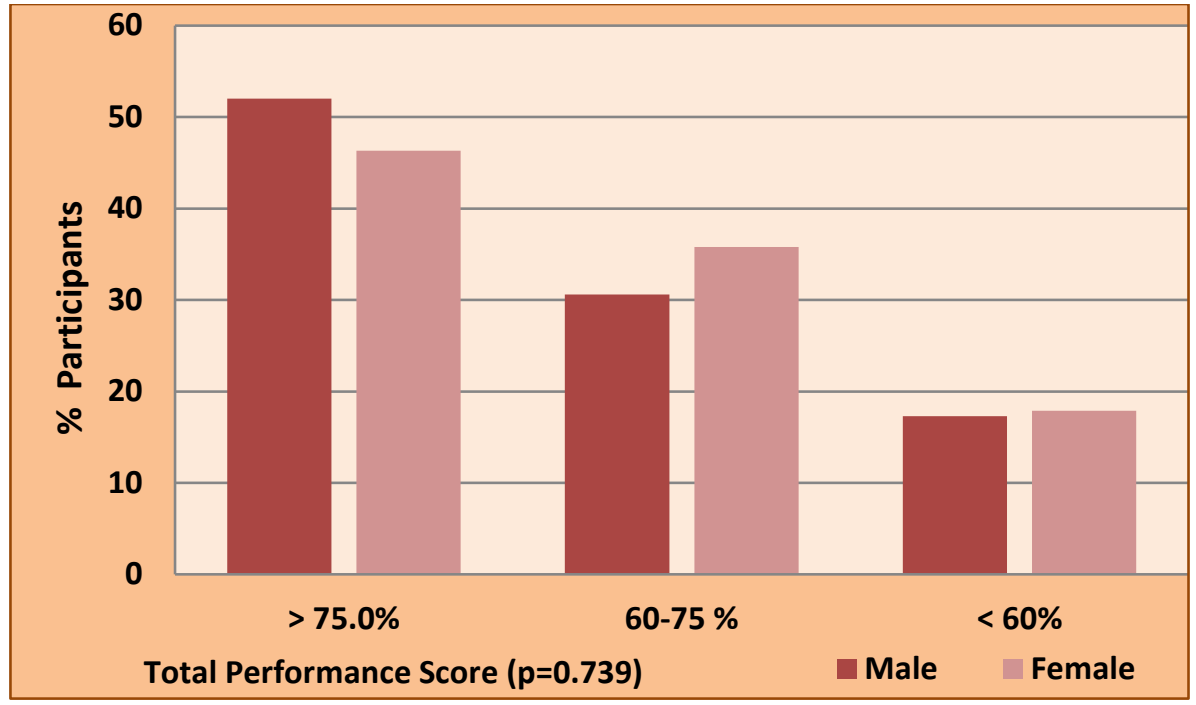

Figure 1: Distribution of studied physicians in relation to gender and

Total performance score of meter-dose inhaler technique

Table 5: Distribution of studied physicians in relation to professional level and Correct performance of meter-dose inhaler technique

\begin{tabular}{|c|c|c|c|c|c|c|c|c|c|}
\hline \multirow[t]{3}{*}{ Procedure } & \multicolumn{8}{|c|}{ Correct Performance } & \multirow{3}{*}{$\begin{array}{l}X^{2} \\
p\end{array}$} \\
\hline & \multicolumn{2}{|c|}{$\begin{array}{c}\text { Consultant } \\
(n=25)\end{array}$} & \multicolumn{2}{|c|}{$\begin{array}{c}\text { Registrar } \\
(n=46)\end{array}$} & \multicolumn{2}{|c|}{$\begin{array}{c}\text { Senior } \\
\text { residence } \\
(n=37)\end{array}$} & \multicolumn{2}{|c|}{$\begin{array}{l}\text { Junior } \\
\text { residence } \\
(n=57)\end{array}$} & \\
\hline & $\mathrm{n}$ & $\%$ & $\mathrm{n}$ & $\%$ & $\mathrm{n}$ & $\%$ & $\mathrm{n}$ & $\%$ & \\
\hline - Remove cap and shake the inhaler vigorously & 25 & 100.0 & 43 & 93.5 & 33 & 89.2 & 44 & 77.2 & $\begin{array}{c}10.97 \\
0.012^{*}\end{array}$ \\
\hline - Breath out slowly and completely & 23 & 92.0 & 39 & 84.8 & 32 & 86.5 & 51 & 89.5 & $\begin{array}{c}1.01 \\
0.797\end{array}$ \\
\hline - Hold the inhaler in the upright position & 10 & 40.0 & 13 & 28.3 & 13 & 35.1 & 11 & 19.3 & $\begin{array}{l}4.79 \\
0.188\end{array}$ \\
\hline $\begin{array}{l}\text { - Insert the mouthpiece into mouth between closed } \\
\text { lips or up to } 4 \text { centimeters in front the open mouth }\end{array}$ & 25 & 100.0 & 34 & 73.9 & 27 & 73.0 & 36 & 63.2 & $\begin{array}{l}12.26 \\
0.007^{*}\end{array}$ \\
\hline - Depress the canister once & 25 & 100.0 & 39 & 84.8 & 35 & 94.6 & 54 & 94.7 & $\begin{array}{c}6.7 \\
0.079\end{array}$ \\
\hline $\begin{array}{l}\text { - At the same time begin slow deep inhalation } \\
\text { continue to total lung capacity (co-ordination) }\end{array}$ & 25 & 100.0 & 42 & 91.3 & 34 & 91.9 & 45 & 78.9 & $\begin{array}{c}9.12 \\
0.028^{*}\end{array}$ \\
\hline - Remove the inhaler with closed lips & 12 & 48.0 & 12 & 26.1 & 16 & 43.2 & 14 & 24.6 & $\begin{array}{l}7.15 \\
0.067\end{array}$ \\
\hline - Hold breaths for $10-15$ seconds. & 20 & 80.0 & 26 & 56.5 & 25 & 67.6 & 42 & 73.7 & $\begin{array}{c}5.31 \\
0.150\end{array}$ \\
\hline $\begin{array}{l}\text { - Wait for } 20-30 \text { seconds before starting the } \\
\text { second puff. }\end{array}$ & 13 & 52.0 & 4 & 8.7 & 13 & 35.1 & 9 & 15.8 & $\begin{array}{c}21.5 \\
0.001^{*}\end{array}$ \\
\hline
\end{tabular}

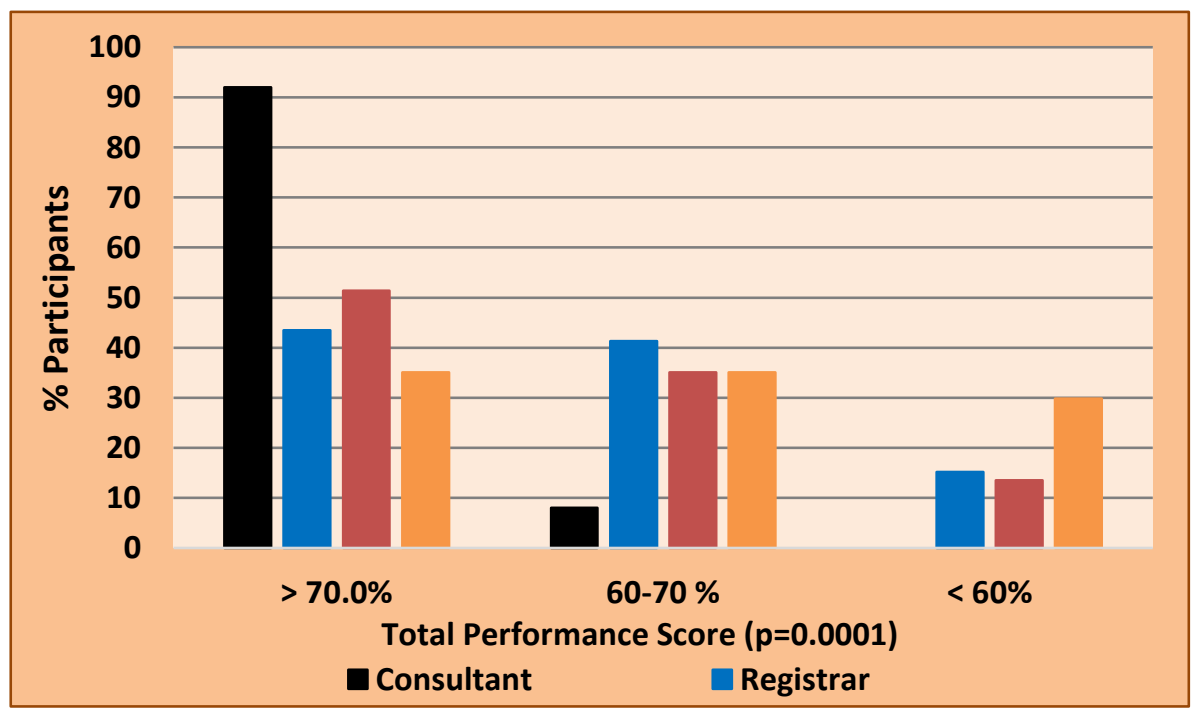

Figure 2: Distribution of studied physicians in relation to position and Total performance score of meter-dose inhaler technique 
Figure 2 shows the distribution of studied physicians in relation to position and total performance score of meter-dose inhaler technique. Professional level was found to affect significantly the total score percentage of performance of metered-dose inhaler $(p=0.001)$. There was a trend of increased percentage of the higher score percentage of $>75 \%$ with increased level of profession. Among junior residents the score of $>75 \%$ was reported among $35.1 \%$ which increased to $51.4 \%$ and $43.5 \%$ among senior residents and registrar, respectively. The highest frequency was reported among consultants who reported a percentage of $92.0 \%$.

\section{DISCUSSION}

The transition from the use of oral to inhaled medications as the preferred route of administration has been one of the most important developments in asthma treatment. The introduction of metered dose inhalers is a major revolution in the therapeutic management of bronchial asthma and chronic obstructive airway disease. These devices enable the direct delivery of medication to the respiratory system, hence reducing the first pass effect .Inhaler therapy is now the recommended mode of delivery of many drugs used in the treatment of asthma and chronic obstructive pulmonary disease. ${ }^{22}$ The major benefits of inhalation therapy are the direct delivery and rapid action of medications in much smaller effective doses compared to systemic routes, thus reducing side-effects. ${ }^{22}$

The important restraint of inhaler devices is that they are more difficult to use and less convenient than tablets. Each inhaler device has its own specific sequence of steps for optimal drug delivery and it is therefore necessary to give careful and correct instruction to patients. ${ }^{21} \mathrm{MDI}$, the most commonly used device, requires the patient to co-ordinate inhalation with action of the device (actuation) which can be difficult for some.22 Patients with asthma have been shown to have poor inhaler using technique, an important cause of poor asthma control. ${ }^{10,11,16}$ As a result, clinical guidelines of International Asthma Management emphasize the importance of demonstrating the correct inhaler technique at initial diagnosis and correcting patient performance at each follow-up visit. 21

In agreement with our study, Raza et al., found that, Junior-most medical residents have grossly sub-optimal performance at steps of MDI use which improves only after individualized demonstration sessions but deteriorate rapidly close to baseline low in difficult-tolearn steps. ${ }^{23}$

Unfortunately, numerous studies consistently show that healthcare providers also have poor inhaler technique. 24,25 The reported rate of correct inhaler technique among various groups of physician is in the range of $28-69 \%$ in different studies with respiratory specialist and internists performing relatively better than others. ${ }^{26}$ For nurses, the reported rate of correct inhaler techniques was within the range of $15-66 \%$ and the respiratory therapists performed better than physicians. ${ }^{27}$

In a different study, asthmatic patients performed better than both physicians and nurses. ${ }^{28}$ In a study from Iran, which included physicians and nurses, only $6.93 \%$ could demonstrate MDIs correctly. ${ }^{29}$ In a study conducted by Hira, established that the doctors who were involved with the MDI use, should learn and become familiar with the proper recommendations for its optimal aerosol delivery. ${ }^{30}$ The poor inhaler technique showed in this study is also due to the lack of any formal training for residents in the correct use of inhalers. However, this universal problem has been shown to improve by formal and regular training of both patients and healthcare providers. ${ }^{31}$

In conclusion, healthcare providers' skills about the MDI technique are limited. Gender had no effect on the performance of each individual when performing the test indicating that the determining factor is the level of training of the participant. This was corroborated by a clear trend between level of professionalism and success of performance of the MDI technique with fully trained consultants scoring the highest on all steps while registrars, senior residents and junior residents scored lower but at different levels for each step. This shows that increased training is the key to correct performance of MDI techniques and should be encouraged further.

Current study indicates implementation of regular trainings and workshops must be conducted for healthcare professionals, especially for junior residents and registrars, evaluation of performance of MDI techniques of junior doctors and healthcare professionals by consultants' can improve outcome of asthma treatment and carrying out more research to ascertain other factors which may help improve efficacy of MDI technique, can improve the efficacy of use of MDI technique by healthcare professionals:

This study is limited in scope as it is confined to prince sultan military medical city, PSMMC, in Al-wazzarat Health Center, Riyadh, KSA. Larger studies across different health care facilities are likely to reveal more representative information to evaluate the ability of family medicine physicians who are working in the family medicine center and family medicine residents in the residency training program to explain the use of metered-dose inhaler in a proper way.

Due to time limitation the investigator used a convenience sample of primary care physicians at one health care center in the kingdom of Saudi Arabia, and thus the results may not be generalizable to other primary health care training centers.

\section{REFERENCES}

1. World Health O. WHO | Asthma. [Updated 2016/03/08/07: 16:00]; Available from: http://www.who.int/respiratory/asthma/en/.

2. World Health O. WHO | Bronchial asthma. [Updated $2016 / 03$ /08/07:19:32]; Available from: http://www.who.int/mediacentre/ factsheets/fs206/en/.

3. Braman SS. The global burden of asthma. Chest. 2006;130(1 Suppl):4S-12S.

4. Saudi Inititive for A. Guidelines for the diagnosis and management of asthma in adults and children. [Updated 2016/03 /08/07:20:44];Available:http://saudithoracic.com/download/SINA\% 20Guidelines\%202016.pdf.

5. Al Frayh AR, Shakoor Z Fau - Gad El Rab MO, Gad El Rab Mo Fau - Hasnain SM, Hasnain SM. Increased prevalence of asthma in Saudi Arabia. 1081-1206 (Print).

6. Global Initiative for Asthma G. Global strategy for asthma management and prevention. [Updated 2016/03/08/07:35:33]; Available from: http://ginasthma.org/wpcontent/uploads/2016/01/GINA_Appendix_2015_May19.pdf. 7. Lim SH, Goh DY, Tan AY, Lee BW. Parents' perceptions towards their child's use of inhaled medications for asthma therapy. J Paediatr Child Health. 1996;32(4):306-9. 
8. Nadi E, Zeraati F, MA. B. Evaluation the rate of correct use of a Metered-Dose inhaler in patients. Scientific Journal of Hamadan University of Medical Sciences \&Health Services. 2002;9(3):31-6.

9. Vella C, Grech V. Assessment of use of spacer devices for inhaled drug delivery to asthmatic children. Pediatr Allergy Immunol. 2005;16(3):258-61.

10. De Blaquiere $P$, Christensen DB, Carter WB, Martin TR. Use and misuse of metered-dose inhalers by patients with chronic lung disease. A controlled, randomized trial of two instruction methods. Am Rev Respir Dis. 1989;140(4):910-6.

11. Thompson J, Irvine T, Grathwohl K, Roth B. Misuse of metered-dose inhalers in hospitalized patients. Chest. 1994;105(3):715-7.

12. Duerden DM, Price D. Training Issues in the Use of Inhalers. Dis-Manage-Health-Outcomes. 2012;9(2):75-87.

13. Brocklebank D, Wright J, Cates C. Systematic review of clinical effectiveness of pressurised metered dose inhalers versus other hand held inhaler devices for delivering corticosteroids in asthma. BMJ. 2001;323(7318):896-900.

14. Brocklebank D, Ram F, Wright J, Barry P, Cates C, Davies L, et al. Comparison of the effectiveness of inhaler devices in asthma and chronic obstructive airways disease: a systematic review of the literature. Health Technol Assess. 2001;5(26):1-149.

15. Baddar SA, Al-Rawas OA, Al-Riyami KA, Worthing EA, Hanssens $\mathrm{YI}$, Taqi AM, et al. Metered-dose inhaler technique among healthcare providers practising in Oman. SQU Journal for Scientific Research - Medical Sciences. 2001;3(1):39-43.

16. Zeraati ENF. Evaluation the rate of correct use of a MeteredDose inhaler in patients. Acta Medica Iranica. 2005;43(4):268-72.

17. Dudyala NS, Amarendra M, Pv S. The Use of Metered Dose Inhalers: Where are we? Journal of Clinical and Diagnostic Research. 2012;6(4):612-14.

18. Stelmach R, Robles-Ribeiro PG, Ribeiro M, Oliveira JC, Scalabrini A, Cukier A. Incorrect application technique of metered dose inhalers by internal medicine residents: impact of exposure to a practical situation. J Asthma. 2007;44(9):765-8.

19. O'Bey KA, Jim LK, Gee JP, Cowen ME, Quigley AE. An education program that improves the psychomotor skills needed for metaproterenol inhaler use. Drug Intell Clin Pharm. 1982;16(12):945-8.

20. Jones JS, Holstege CP, Riekse R, White L, Bergquist $T$. Metered-dose inhalers: do emergency health care providers know what to teach? Ann Emerg Med. 1995;26(3):308-11.

21. Scheffer AL, editor. Global strategy for asthma management and prevention. NHLB. WHO Workshop; 1995 1995. Bethesda.

22. Self TH, Rumbak MJ, Kelso TM. Correct use of metered-dose inhalers and spacer devices. Postgraduate medicine. 1992;92(3):95-6, 9-103, 6.
23. Raza MA, Khan MIH. Learning and Recall of Metered Dose Inhaler Technique amongst Junior Medical Residents in a Teaching Hospital. Pakistan Journal of Medical and Health Sciences. 2012;6(2):444-9.

24. Self TH, Brooks JB, Lieberman P, Ryan MR. The value of demonstration and role of the pharmacist in teaching the correct use of pressurized bronchodilators. Can Med Assoc J. 1983;128(2):129-31.

25. Kelling JS, Strohl KP, Smith RL, Altose MD. Physician knowledge in the use of canister nebulizers. CHEST Journal. 1983;83(4):612-4.

26. Plaza V, Sanchis J. Medical personnel and patient skill in the use of metered dose inhalers: a multicentric study. CESEA Group. Respiration. 1998;65(3):195-8.

27. Self TH, Kelso TM, Arheart KL, Morgan JH, Umberto Meduri G. Nurses' performance of inhalation technique with metered-dose inhaler plus spacer device. Ann Pharmacother. 1993;27(2):185-7. 28. Verver S, Poelman M, Bögels A, Chisholm SL, Dekker FW. Effects of instruction by practice assistants on inhaler technique and respiratory symptoms of patients. A controlled randomized videotaped intervention study. Fam Pract. 1996;13(1):35-40.

29. Nadi E, Zeraati F. Evaluation of the metered-dose inhaler technique among healthcare providers. Acta Medica Iranica. 2005;43(4):268-72.

30. Hira HS. Faulty use of metered dose inhalers by physicians. $J$ Assoc Physicians India. 1994;42(7):524-5.

31. Jackevicius CA, Chapman KR. Inhaler education for hospitalbased pharmacists: how much is required? Can Respir J. 1999;6(3):237-44.

\section{Source of Support: Nil.}

\section{Conflict of Interest: None Declared.}

Copyright: () the author(s) and publisher. IJMRP is an official publication of Ibn Sina Academy of Medieval Medicine \& Sciences, registered in 2001 under Indian Trusts Act, 1882.

This is an open access article distributed under the terms of the Creative Commons Attribution Non-commercial License, which permits unrestricted non-commercial use, distribution, and reproduction in any medium, provided the original work is properly cited.

Cite this article as: Mohammed A. Al Zamil, Rabaa Al Momen. Performance Evaluation of the Metered-Dose Inhaler Technique among Healthcare Providers. Int J Med Res Prof. 2016; 2(6):196201. DOI:10.21276/ijmrp.2016.2.6.041 